\title{
Molecular Therapeutics in Development for Epidermolysis Bullosa: Update 2020
}

\author{
Cristina $\operatorname{Has}^{1}$ (D) Andrew South ${ }^{2} \cdot$ Jouni Uitto ${ }^{2}$
}

Published online: 23 April 2020

(c) The Author(s) 2020

\begin{abstract}
Epidermolysis bullosa (EB) is a group of rare genetic disorders for which significant progress has been achieved in the development of molecular therapies in the last few decades. Such therapies require knowledge of mutant genes and specific mutations, some of them being allele specific. A relatively large number of clinical trials are ongoing and ascertaining the clinical efficacy of gene, protein or cell therapies or of repurposed drugs, mainly in recessive dystrophic EB. It is expected that some new drugs may emerge in the near future and that combinations of different approaches may result in improved treatment outcomes for individuals with EB.
\end{abstract}

\section{Introduction}

Epidermolysis bullosa (EB) comprises a group of genetic disorders characterized by fragility of the skin and mucosal membranes. The molecular basis involves pathogenic variants in genes encoding structural proteins of the dermal-epidermal junction zone (DEJZ) [1]. As a consequence of missing or dysfunctional molecules (e.g., keratins $5 / 14$, integrin $\alpha 6 \beta 4$, type XVII and VII collagens), reduced epidermal-dermal cohesion results in blisters after minimal mechanical trauma. The clinical severity of EB covers a broad spectrum, ranging from minor skin or nail involvement and minimal disease burden in localized subtypes to early lethality or life-long progressive systemic disease in severe subtypes [2].

EB is a prototypic disorder for which molecular therapies have been under development in the last few decades. Significant progress has been achieved in understanding the molecular pathogenesis of EB and the potential

Cristina Has and Andrew South contributed equally.

Cristina Has

cristina.has@uniklinik-freiburg.de

1 Department of Dermatology, Faculty of Medicine, University of Freiburg, Hauptstr. 7, 79104 Freiburg, Germany

2 Department of Dermatology and Cutaneous Biology, Sidney Kimmel Medical College, and The Joan and Joel Rosenbloom Research Center for Fibrotic Diseases, and Jefferson Institute of Molecular Medicine, Thomas Jefferson University, Philadelphia, PA, USA

\section{Key Points}

Remarkable progress has been made in understanding the molecular genetics and underlying pathomechanisms of epidermolysis bullosa (EB) forming the platform for development of treatments.

Gene-replacement approaches, particularly delivery of COL7A1 to the skin of patients with severe dystrophic $\mathrm{EB}$, type VII collagen replacement, skipping of exons and read-through of premature termination codons are currently in clinical trials.

Preclinical research explores the applicability of new strategies in regenerative medicine (e.g., induced pluripotent stem cells) and genome editing (e.g., CRISPR/ Cas9).

Particular effort is focused on severe dystrophic EB, characterized by extensive scarring and aggressive squamous cell carcinomas. Small molecules repurposed to reduce fibrosis, and the multikinase inhibitor rigosertib-for the treatment of recessive dystrophic EB squamous cell carcinomas-are being tested in clinical trials. 
benefits and limitations of different therapeutic approaches [3]. Considering that EB is a rare disease, a relatively large number of clinical trials are ongoing and ascertaining the clinical efficacy of gene, protein or cell therapies or of repurposed drugs (Table 1). In parallel, preclinical research explores the applicability of new strategies in regenerative medicine (e.g., induced pluripotent stem cells [iPSCs]) and genome editing (e.g., CRISPR/Cas9) (Table 2). However, the initial hope of rapid translation from bench to bedside has been tempered by multiple hurdles and challenges, including the complexity of EB itself. Thus, instead of attempting to cure EB, researchers are increasingly aiming at "symptom-relieving" or "diseasemodifying" therapies.

\section{Molecular Pathology of Epidermolysis Bullosa (EB)}

Pathogenic variants in 16 genes cause the four main subtypes of classical EB: EB simplex (EBS), junctional EB (JEB), dystrophic EB (DEB) and Kindler EB; over 30 EB subtypes are further defined based on clinical and molecular criteria [2]. EBS and JEB are genetically heterogeneous, whereas DEB and Kindler EB are caused by mutations in single genes, COL7A1 and FERMT1, respectively. In addition to the classical forms of EB, five additional genes have been associated with skin fragility disorders in differential diagnosis of EB. Thus, a total of 21 genes are known to harbor mutations in skin fragility disorders in the spectrum of EB.

The determinants of the EB phenotype include the identity of the affected gene/protein system and the specific nature of the disease-causing genetic variants. Specifically, residual amounts or functions of the affected protein versus its complete absence or loss-of-function determine whether the disease will be relatively mild, intermediate or severe. Examples of genotype-phenotype correlations in patients with JEB and DEB have shown that small amounts (even less than $10 \%$ ) of proteins with partial function may result in a mild/intermediate phenotype [4-7]. Genetic and epigenetic disease modifiers may also play a modulating role but have only been experimentally demonstrated in a few cases [8-12], and such findings have to be extrapolated to larger numbers of patients to allow general conclusions. Socio-economic environment and access to medical care are also critical elements in determining the natural history of the disease and the development of complications in individual cases.

Although multiple different proteins are affected, it is widely accepted that all EB types have life-long skin fragility in common and this pathology (disruption of the barrier function of the skin and mucous membranes) leads to chronic tissue damage and associated inflammation. Loss of epidermal integrity is accompanied by bacterial colonization and activation of mechanisms of innate and adaptive immunity. The cytokines engaged in the tissue damage/ repair processes depend on the extent of the mucocutaneous defects and on the level of blister formation (implying either cytolysis or basement membrane zone disruption), and include interleukin (IL)-1, IL-6 and transforming growth factor (TGF)- $\beta$ [13-15]. With time, the ongoing regeneration processes affect the stem cells and the underlying connective tissue, leading to chronic, non-healing wounds. If these events affect a significant percentage of the body surface (such as more than 20-30\% at any given time) over a long period, the "inflammation" becomes systemic, as shown by leukocytosis, increased $\mathrm{C}$ reactive protein and increased levels of immunoglobulins (IgG, $\operatorname{IgM}$ and $\operatorname{IgA}$ ) [16]. In recessive DEB (RDEB), involvement of the oral and esophageal mucosa impairs feeding, and - together with the high energetic requirements in the context of permanent wound healing - will lead to impaired growth and low body weight. The EB-associated symptoms-pain and pruritus-are mainly related to mucocutaneous blistering and wounding. A longterm complication of chronic tissue damage is carcinogenesis, which is reflected by high risk for squamous cell carcinomas (SCCs) at a young age in patients with RDEB [17] and Kindler EB [18, 19]. Based on these considerations, the main rationale for therapy should be the correction of the skin adhesion defect as this is traditionally accepted as the main origin of pathogenic events in EB.

\section{Precision Medicine for EB: From Genetic Defect to Therapeutic Approach}

In EB, knowledge of the precise underlying genetic defect is the prerequisite for any molecular therapy approach. The affected gene or protein and the type of pathogenic variants and their consequences dictate which gene or protein should be replaced or edited (e.g., gene or protein therapy). Patients with premature termination codon (PTC) mutations in any EB gene may benefit from read-through therapies [20-23]. Mutations in the type VII (COL7A1) and XVII (COL17A1) collagen genes, in which the majority of the exons are in frame, may be approached by skipping of the exons containing the mutations [24]. In the autosomal-dominant forms of EBS and in dominant DEB, the vast majority of mutations lead to amino acid substitutions that disturb the formation and the stability of the keratin intermediate filaments or anchoring fibrils, respectively, through dominant-negative interference of the wild-type allele. For such mutations, potential strategies include knock-down/out of the mutated allele (e.g., by small interfering RNA, RNA 
trans-splicing or CRISPR/Cas9) [25, 26] or prevention of misfolding (e.g., with chaperones). More palliative (and less precise) approaches include the so-called symptom-relieving therapies, which are directed against inflammatory or other perturbed pathways (e.g., IL-1 $\beta$, TGF $\beta$ ). Generation of dedicated databases of EB-associated pathogenic variants comprising their biological characterization, such as consequences at splicing, protein and cellular levels as well as allele frequencies, would be of benefit for researchers and physicians dealing with EB and would assist in setting priorities for specific strategies and in stratification of patients for therapies.

\section{Overview of Molecular Therapies in Development for EB}

Various molecular therapies are currently in preclinical or clinical development, and most of these focus on RDEB. An overview of the recent advances in those currently under development follows.

\subsection{Gene-Replacement Therapies}

Many laboratories, in both academia and the pharmaceutical sector, have focused on gene-replacement approaches, particularly delivery of $C O L 7 A 1$ to the skin of patients with RDEB (Table 1). For details on methods, hurdles and risks, we refer to recent review articles [27, 28]. Some studies have tested the efficacy of topical application of an expression vector harboring full-length COL7A1 complementary DNA (cDNA), which would then allow expression of the proo1(VII) polypeptides in the skin, followed by their incorporation into trimeric type VII collagen molecules and supramolecular assembly into functional anchoring fibrils.

In one such approach (Krystal Biotech, Inc.), the cDNA is packaged into a herpes simplex virus (HSV) delivery construct with epidermotropism. In this case, the HSV virus, which in its natural form is highly antigenic, has been modified to manifest with reduced immunogenicity, which would prevent development of immunological complications, such as formation of antibodies, which would eliminate the viral vector and preclude multiple applications (NCT03536143). Another topical application (Amryt Pharma, PLC) utilizes a recently developed non-viral carrier, a highly branched poly $(\beta$-ester) polymer, that allows delivery of the COL7A1 cDNA into the skin. In both cases, the transgene does not integrate into the recipient's genome, and continuousperhaps life-long-application is required to achieve sustained benefits from the treatment. Current early clinical trials are exploring the frequency of application required for maintenance of efficacy and are examining the levels of expression and turnover time of type VII collagen and its potential assembly into anchoring fibrils.

Another approach for delivery of COL7A1 into patients with RDEB entails introduction of the transgene into the patient's own cells in cultures, with subsequent delivery of the corrected cells back into the skin. One such approach (Castle Creek Biosciences, Inc.) corrects autologous fibroblasts in culture with a vector that leads to integration of the transgene into the genome, followed by direct injection of the corrected cells to the edges of the wounds. This approach necessitates multiple injections, which can be painful, to the eroded areas of skin, and how long the corrected resident fibroblasts are present and remain active in situ is unclear. Another company (Abeona Therapeutics, Inc.) cultures autologous keratinocytes from the skin of patients with RDEB, followed by genetic correction ex vivo and development of epidermal sheaths, which can then be grafted to the denuded areas of the patient's skin [29, 30]. These studies have utilized a lentiviral vector that allows incorporation of the COL7A1 cDNA into the genome of the recipient cells. Preliminary studies have revealed that the gene-corrected keratinocytes in the graft are capable of expressing type VII collagen, and there is evidence of assembly of anchoring fibrils. Of some concern is the durability of this approach since the early published data suggested that the expression of the collagen gene may fade over time, possibly attesting to the fact that the transgene is driven by a viral promoter or that the number of stem cells initially isolated and targeted were too low to sustain expression or possibly the graft [31]. Furthermore, in some cases, the graft fails after a certain time, potentially necessitating regrafting of the area. In this context, a recent study demonstrated that correction of both keratinocytes and fibroblasts (cell types that in normal skin both synthesize type VII collagen) is required for optimal assembly of the anchoring fibrils [32]. In this study, skin grafts were made by combining gene-corrected keratinocytes with type VII collagen-deficient fibroblasts, or, conversely, type VII collagen-deficient keratinocytes in combination with gene-corrected fibroblasts, or both cell types being gene corrected. All these three combinations of cells in skin-equivalent explant culture ex vivo expressed type VII collagen, but only the grafts in which both keratinocytes and fibroblasts were gene corrected showed assembly of functional anchoring fibrils. In keeping with these data, there is an ongoing effort to develop skin grafts (GENEGRAFT) that combine keratinocytes and fibroblasts in which both cell types have been corrected with a self-inactivating viral vector expressing type VII collagen [33].

Epidermal grafts have been shown to be highly successful in correcting the underlying defect in patients with intermediate or localized JEB with defects in one of the laminin 332 genes, LAMB3 [33-35]. The difference with these studies 
Table 1 Gene-replacement therapies for epidermolysis bullosa in clinical trials

\begin{tabular}{|c|c|c|c|c|c|}
\hline Gene therapy trial & EB type/protein & Approach & $\begin{array}{l}\text { Par- } \\
\text { tici- } \\
\text { pants } \\
(\mathrm{N})\end{array}$ & Results & References \\
\hline Phase I & $\begin{array}{l}\text { JEB/laminin } \beta 3 \\
\text { chain }\end{array}$ & $\begin{array}{l}\text { Ex vivo genetically corrected } \\
\text { (retroviral) autologous epi- } \\
\text { dermal grafts }\end{array}$ & 2 & $\begin{array}{l}\text { One } 7 \text {-year-old child treated in } \\
\text { wounds covering } 80 \% \text { of the } \\
\text { total body surface resulted in } \\
\text { regeneration of entire epider- } \\
\text { mis by transgenic stem cells } \\
\text { stable over several years. } \\
\text { One } 49 \text {-year-old woman was } \\
\text { successfully treated on an } \\
80 \mathrm{~cm}^{2} \text { chronic wound }\end{array}$ & {$[35,36]$} \\
\hline $\begin{array}{l}\text { Phase I/II; NCT03490331 } \\
\text { (HOLOGENE17) }\end{array}$ & JEB/C17 & $\begin{array}{l}\text { Ex vivo grafting of gene-cor- } \\
\text { rected epidermal sheets with } \\
\text { a gamma-retroviral vector } \\
\text { carrying COL17A1 cDNA }\end{array}$ & 12 & Ongoing & $\begin{array}{l}\text { [91] } \\
\text { https://clinicaltrials.gov/ct2/ } \\
\text { show/NCT03490331 }\end{array}$ \\
\hline $\begin{array}{l}\text { Phase I/II; NCT02984085 } \\
\text { (HOLOGENE7) }\end{array}$ & $\mathrm{RDEB} / \mathrm{C} 7$ & $\begin{array}{l}\text { Ex vivo grafting of gene-cor- } \\
\text { rected epidermal sheets with } \\
\text { a gamma-retroviral vector } \\
\text { carrying COL7A1 cDNA }\end{array}$ & 12 & Ongoing & $\begin{array}{l}\text { [91] } \\
\text { https://clinicaltrials.gov/ct2/ } \\
\text { show/NCT02984085 }\end{array}$ \\
\hline $\begin{array}{l}\text { Phase I; safety and wound } \\
\text { outcomes; single center }\end{array}$ & RDEB/C7 & $\begin{array}{l}\text { Ex vivo genetically corrected } \\
\text { (retroviral) autologous epi- } \\
\text { dermal grafts of } 35 \mathrm{~cm}^{2}\end{array}$ & 4 & $\begin{array}{l}\text { Variable response of wound } \\
\text { healing and C7; generally } \\
\text { declined over } 1 \text { year }\end{array}$ & [30] \\
\hline Phase I/IIa; single center & $\mathrm{RDEB} / \mathrm{C} 7$ & $\begin{array}{l}\text { Ex vivo genetically corrected } \\
\text { (retroviral) autologous epi- } \\
\text { dermal grafts of } 35 \mathrm{~cm}^{2}\end{array}$ & 7 & $\begin{array}{l}\text { C7 expression persisted up to } \\
2 \text { years after treatment in } \\
\text { two participants. Treated } \\
\text { wounds with } \geq 50 \% \text { healing } \\
\text { demonstrated improvement } \\
\text { in patient-reported pain, itch, } \\
\text { and wound durability }\end{array}$ & [29] \\
\hline Phase I; single center & $\mathrm{RDEB} / \mathrm{C} 7$ & $\begin{array}{l}\text { Three intradermal injections } \\
\left(\sim 1 \times 10^{6} \mathrm{cells} / \mathrm{cm}^{2} \text { of intact }\right. \\
\text { skin) of } C O L 7 A 1 \text {-modified } \\
\text { (lentiviral) autologous } \\
\text { fibroblasts }\end{array}$ & 4 & $\begin{array}{l}\text { C7 restoration in vivo in treated } \\
\text { skin at } 1 \text { year after gene } \\
\text { therapy }\end{array}$ & [92] \\
\hline $\begin{array}{l}\text { Phase I/II, phase III; } \\
\text { NCT04213261 (Castle Creek } \\
\text { Biosciences, Inc.) }\end{array}$ & $\mathrm{RDEB} / \mathrm{C} 7$ & $\begin{array}{l}\text { COL7A1-corrected autologous } \\
\text { fibroblasts injected in the } \\
\text { wounds }\end{array}$ & 20 & Ongoing & $\begin{array}{l}\text { https://clinicaltrials.gov/ct2/ } \\
\text { show/NCT04213261 }\end{array}$ \\
\hline $\begin{array}{l}\text { Phase III; NCT04227106 } \\
\text { (Abeona Therapeutics Inc.) }\end{array}$ & $\mathrm{RDEB} / \mathrm{C} 7$ & $\begin{array}{l}\text { Transplantation of ex vivo } \\
\text { COL7A1-corrected autolo- } \\
\text { gous keratinocyte sheets }\end{array}$ & 15 & Ongoing & $\begin{array}{l}\text { https://clinicaltrials.gov/ct2/ } \\
\text { show/NCT04227106 }\end{array}$ \\
\hline $\begin{array}{l}\text { Phase I/II; European (GENE- } \\
\text { GRAFT) }\end{array}$ & $\mathrm{RDEB} / \mathrm{C} 7$ & $\begin{array}{l}\text { Skin-equivalent grafts ex vivo } \\
\text { genetically corrected with } \\
\text { a COL7A1-encoding SIN } \\
\text { retroviral vector }\end{array}$ & 4 & Ongoing & [33] \\
\hline $\begin{array}{l}\text { Phase I/II; NCT03536143 } \\
\text { (Krystall Biotech, Inc.) }\end{array}$ & $\mathrm{RDEB} / \mathrm{C} 7$ & $\begin{array}{l}\text { Topically administered, } \\
\text { replication-deficient HSV-1 } \\
\text { vector containing two func- } \\
\text { tional } C O L 7 A 1 \text { genes applied } \\
\text { directly to wounds }\end{array}$ & 6 & Ongoing & $\begin{array}{l}\text { www.krystalbio.com/focus/about } \\
\text {-dystrophic-eb/ }\end{array}$ \\
\hline Phase I (Amryt Pharma, PLC) & $\mathrm{RDEB} / \mathrm{C} 7$ & $\begin{array}{l}\text { Topically administered syn- } \\
\text { thetic polymer polyplexes } \\
\text { containing } C O L 7 A 1, \text { applied } \\
\text { directly to wounds }\end{array}$ & NA & NA & $\begin{array}{l}\text { https://www.amrytpharma.com/ } \\
\text { patients-and-carers/gene-thera } \\
\text { py/ }\end{array}$ \\
\hline
\end{tabular}

cDNA complementary DNA, $C 7$ type VII collagen, $C 17$ type XVII collagen, $E B$ epidermolysis bullosa, $H S V$ - 1 herpes simplex virus type 1 , JEB junctional EB, $N A$ not available, $R D E B$ recessive dystrophic $\mathrm{EB}$, SIN self-inactivating 
Table 2 Overview of recently published CRISPR/Cas9- and RNA-based molecular therapies in preclinical development

\begin{tabular}{|c|c|c|c|}
\hline Molecular therapy approach & EB type/gene & Correction type, targeted mutation and cells & References \\
\hline \multirow{11}{*}{$\begin{array}{l}\text { Genomic editing using the } \\
\text { CRISPR/Cas9 nuclease } \\
\text { system }\end{array}$} & \multirow[t]{9}{*}{$\mathrm{RDEB} / C O L 7 A 1$} & COL7A1 overexpression & [93] \\
\hline & & Correction of a mutation in exon 2 & [41] \\
\hline & & Correction of the mutation c. $4317 \mathrm{delC}$ and generation of iPSC & [94] \\
\hline & & $\begin{array}{l}\text { Correction of mutations in exon } 19 \text { (c.2470insG) and exon } 32 \text { (c.3948insT) } \\
\text { through homology-directed repair in iPSC }\end{array}$ & [42] \\
\hline & & Gene reframing therapy to a recurrent frameshift mutation, c.5819delC & [43] \\
\hline & & Correction of the mutation c.8068_8084delinsGA & [95] \\
\hline & & $\begin{array}{l}\text { Cas9/sgRNA ribonucleoproteins to excise exon } 80 \text { in skin stem cells of recessive } \\
\text { dystrophic EB mice }\end{array}$ & [96] \\
\hline & & $\begin{array}{l}\text { Targeted deletion of mutation-bearing COL7A1 exon } 80 \text { in RDEB patient keratino- } \\
\text { cytes }\end{array}$ & [39] \\
\hline & & Correction of a frequent inherited mutation in exon 80 & [40] \\
\hline & $\mathrm{JEB} / L A M B 3$ & In situ correction of $L A M B 3$ gene in keratinocytes & [97] \\
\hline & $\mathrm{EBS} / K R T 14$ & Correction of the hotspot missense mutation c. $1231 \mathrm{G}>\mathrm{A}$ in keratinocytes & [26] \\
\hline \multirow[t]{6}{*}{ RNA-based therapies } & \multirow[t]{5}{*}{$\mathrm{RDEB} / \mathrm{COL} 7 \mathrm{Al}$} & Trans-splicing to correct mutations in the $3^{\prime}$ region & [98] \\
\hline & & $\begin{array}{l}\text { SIN lentiviral vector at } 3^{\prime} \text { RNA trans-splicing molecule, capable of replacing exons } \\
65-118\end{array}$ & [99] \\
\hline & & 2'-O-methyl ASO for skipping exons 73 and 80 & {$[58]$} \\
\hline & & ASO for in-frame exon 105 skipping & [59] \\
\hline & & ASO for in-frame exon 13 and 105 skipping & {$[60]$} \\
\hline & $\mathrm{EBS} / K R T 14$ & Therapeutic RNA trans-splicing molecule containing wild-type exons 1-7 & {$[25]$} \\
\hline
\end{tabular}

$A S O$ antisense oligonucleotides, $E B$ epidermolysis bullosa, $E B S$ EB simplex, $i P S C$ induced pluripotent stem cells, $J E B$ junctional EB, $R D E B$ recessive dystrophic $\mathrm{EB}$, SIN self-inactivating

and those published on grafting in patients with RDEB is that the grafts for patients with JEB were made of a holoclone stem cell population, thus ensuring the longevity of the cells after transplantation. In fact, in one patient with JEB, the functionality of the skin grafts was retained several years after the transplantation [36]. The difference in the outcome between the epidermal cells corrected for transplantation into patients with RDEB and JEB may also reside in the observation that, in normal skin, the laminin 332 polypeptide subunit genes, $L A M A 3, L A M B 3$ and $L A M C 2$, provide a selective advantage for retaining stem cells in vivo [37, 38].

\subsection{Gene Editing}

In addition to gene-replacement approaches, a number of studies have attempted gene repair, such as correction of the mutation by CRISPR/Cas9 editing technology [39-43] (Table 2). For details on gene-editing strategies and their appropriate selection depending on mutation, gene and disease type, we refer to a recent overview article [44]. Improvements in this technology have resulted in a high yield of gene correction in keratinocytes or fibroblasts derived from patients with RDEB, with subsequent development of skin grafts that have been transplanted into immunocompromised mice, demonstrating their capability of functional type VII collagen synthesis. One of the potential limitations of this approach is the requirement for a large number of cultured cells for graft production, and an innovative way to circumvent this limitation would be the development of iPSCs that, following the gene correction, can be differentiated into either keratinocytes or fibroblasts [42, 45].

\subsection{Natural Gene Therapy}

An intriguing possibility for cell-based therapy in EB is provided by revertant mosaicism, a phenomenon described as "natural gene therapy," in which a number of skin cells undergo spontaneous reversal of the mutation to wild-type genotype, resulting in areas of normal skin [46, 47]. The mechanisms of the mutation reversion are multiple, including mitotic recombinations, back mutations and second site mutations [48-50].

Revertant mosaicism in patients with RDEB has been primarily documented in keratinocytes, but evidence of revertant mosaic fibroblasts has also recently been reported [51]. Attempts to establish long-term cultures of keratinocytes from areas of skin with revertant mosaicism have been mostly unsuccessful, primarily due to depletion of stem cells in the affected skin. However, punch grafting of revertant skin to isolated lesions in patients with laminin 332-deficient JEB has been reported [52]. Transplantation of the biopsy specimens resulted in re-epithelialization of the wounds, 
but punch grafting allowed only a limited expansion of the revertant skin [53]. However, expansion of the treated area can be achieved by generation of iPSCs from revertant keratinocytes, and these cells can then be differentiated into genetically corrected keratinocytes [45]. These revertant iPSCs can be used to create three-dimensional skin equivalents ex vivo and reconstitute human skin in vivo, developing cell-based therapeutic approaches for EB.

\subsection{Exon Skipping}

Exon skipping makes use of antisense oligonucleotides (ASOs) to modify the splicing of pre-messenger RNA (mRNA) and consequently eliminate the mutation responsible for a disease. Antisense-mediated exon skipping was initially developed for the treatment of Duchenne muscular dystrophy (DMD) and evolved into clinical trials to target $D M D$ (dystrophin gene) exons with recurrent mutations, such as exons 45, 53 and 51. Eteplirsen (Exondys 51) is the first approved antisense therapy for DMD in the USA and provides a treatment option for the $\sim 14 \%$ of patients with DMD who are amenable to exon 51 skipping [54].

The rationale for using exon skipping in EB comes from studies of genotype-phenotype correlations showing that exon skipping can ameliorate the severity of JEB and DEB [4, 55-57] and from the fact that most COL17Al and COL7A1 exons are in frame. Several preclinical studies have demonstrated that skipping of exons $13,70,73,80$ or 105 in COL7A1 results in slightly shortened, partially functional protein, which is deposited at the DEJZ [58-61] (Table 2). A clinical trial testing topical administration of QR-313, a water-based gel (hydrogel) containing the ASO targeting exon 73 that will be applied directly onto DEB wounds for COL7A1 correction is currently ongoing (Wings Therapeutics; NCT03605069).

\subsection{Protein Therapy}

Preclinical studies have shown that recombinant type VII collagen, injected locally or intravenously, homes to the DEJZ and promotes wound healing [62, 63]. Recombinant type VII collagen has obtained fast drug designation from the US FDA, and a phase I/II clinical trial evaluating its safety and tolerability, as well as clinical proof of concept in adults with RDEB, is ongoing in the USA (Phoenix Tissue Repair, Inc.; NCT03752905). The advantages of systemically administered recombinant type VII collagen include the possibility that the protein, in addition to homing into skin, will reach extracutaneous tissues affected by RDEB, such as the gastrointestinal track and the cornea of the eye, with subsequent repair.

Beside this protein-replacement approach, a therapy with a high mobility group box 1 (HMGB1) fragment is under development (redasemtide trifluoroacetate phase II, Shinogi \& Co., Ltd.). HMGB1 can mobilize the Lin(-)/PDGFR $\alpha(+)$ cells from bone marrow to damaged tissue and facilitate tissue repair [64], probably by suppressing the inflammation of injured skin [65]. In animal models, systemic administration of the HMGB1 fragment has shown benefits, preventing deterioration of cardiac performance in the delta-sarcoglycan-deficient hamster [66] and ameliorating cutaneous and non-cutaneous manifestations in a dystrophic EB model mouse [67].

\subsection{Read-Through Therapies}

The read-through approach involves the use of small-molecular-weight compounds that allow the translational machinery to suppress nonsense mutations by incorporating an amino acid in place of a stop codon and results in synthesis of full-length protein.

The original prototype of such read-through molecules, PTC124, was shown to read-through only pathogenic PTCs but not through naturally occurring endogenous stop codons of translation because the nucleic acid context and the intron-exon organization of the gene provide a very robust and strong stop signal. This read-through molecule has been tested on a number of genes, principally the dystrophin gene in DMD [68], but some studies have failed to identify PTC124 as being able to efficiently read-through COL7A1 PTCs as compared with the prototypic PTC read-through drug, the aminoglycoside gentamicin [20, 23, 69]. Work has shown that gentamicin can effectively read-through COL7A1 and LAMB3 PTCs [20, 21], and clinical studies in RDEB have shown promising results [22]. Long-term systemic treatment with this antibiotic has a number of potential issues, including the risk of renal toxicity [70], and topical application might be a favorable delivery route in this context. Nevertheless, clinical studies testing the effect of intravenous injections of gentamicin are being conducted for RDEB (NCT03392909) and JEB (NCT03526159).

Another compound recently shown to induce readthrough of COL7Al is amlexanox [71], a drug with a number of different activities and targets currently in trial for a wide range of indications. This drug could potentially be used long term because of its very favorable toxicity profile and clinical history. However, the current manufacturer of amlexanox, Takeda Pharmaceutical, has removed it from the market, and an alternative supply will be needed to pursue clinical application. One interesting observation from the amlexanox study in EB was that it enhanced read-through only in cells with a low level of endogenous full-length protein, whereas cells with undetectable protein did not respond [23]. These data suggest that certain cellular conditions required for read-through need to be identified and exploited for more efficient and effective approaches. 


\subsection{Small Molecules Repurposed to Relieve Symptoms}

Fibrosis is a major pathological complication of RDEB, and work with patient cells in culture, animal models and patients have all identified TGF $\beta$ signaling as a major driver of fibrosis and disease severity [9, 72-75]. TGF $\beta$ is a primary mediator of fibrosis driving extracellular matrix (ECM) deposition in numerous pathological situations, and considerable effort has focused on understanding and inhibiting TGF $\beta$ in a number of contexts [76]. However, as TGF $\beta$ receptors participate in a signaling pathways that control many aspects of mammalian development and tissue homeostasis, global inhibition has proven problematic [77]. Indirect targeting of molecules that activate or inhibit the pathway in specific contexts will likely have improved efficacy compared with global inhibition. The first example of such an approach in RDEB is the use of losartan, a drug approved for the treatment of high blood pressure. Work in animal models identified a significant reduction of fibrosis in the paws of hypomorphic mice with losartan treatment, and this drug is now in a clinical trial (EudraCT number: 2015-003670-32) [78]. The mechanism here is thought to be a reduction in blood pressure, which reduces the bioavailability or release of TGF $\beta$ ligand from the fibrotic ECM. Other preclinical efforts have used viral delivery of decorin, an inhibitor of TGF $\beta$, to show reduced paw fibrosis in mouse models [79], whereas in vitro work with patient cells has suggested that inhibition of thrombospondin-1, a potent activator of TGF $\beta$, may have clinical efficacy [72]. In addition to these academic-led initiatives, a number of anti-TGF $\beta$ antibodies are in development in the commercial space that have potential to reach clinical trial in the coming years.

\section{Therapies for EB-Associated Squamous Cell Carcinoma}

Historically, only a few reports have documented any durable therapeutic response of SCCs in patients with RDEB, and the observations that reported short-term responses were not followed-up in the literature [80]. However, additional case studies and reviews of prior literature are beginning to emerge, and the main focus has been on cetuximab, the epidermal growth factor receptor inhibitor approved for head and neck SCC (HNSCC) [81]. A number of patients with RDEB have been treated, and progression-free survival has been reported to range between 3 and 9 months, but woundhealing deficits are often noted, and eventually the patients may succumb to their disease [82-86]. With the recent approval of the immune checkpoint inhibitors nivolumab, pembrolizumab and cemiplimab, the treatment landscape of HNSCC and cutaneous SCC is changing, and long-term progression-free survival in a small proportion of patients with spontaneous SCC is becoming evident [87, 88]. For two patients with RDEB SCC treated with nivolumab, the results were negative, with no evidence of durable response $[82,86]$. However, two patients are too few to rule out potential benefits, considering that only $20 \%$ of patients with HNSCC show a response to this therapeutic approach. One phase I clinical trial testing the toxicity of isotretinoin in RDEB SCC has been reported [89]. Although the drug was well-tolerated by 20 patients, no further studies were conducted. Preclinical work identified the potential of the multikinase inhibitor rigosertib, an experimental therapeutic in phase III trials for treatment of myelodysplastic syndrome and RDEB SCC [90]. In cell culture and animal studies, rigosertib induced apoptosis in RDEB SCC without adversely affecting nonSCC RDEB epidermal keratinocytes. As a result, two trials, one in the USA (NCT04177498) and one in the UK and Austria (NCT03786237), have been initiated.

\section{Conclusions and Future Perspectives}

Tremendous progress has been made in understanding the molecular genetics and underlying pathomechanisms of different forms of $\mathrm{EB}$, and the increase in knowledge about these disorders has formed the basis for treatment development. Several laboratories in academia, a number of companies and biotechnology and the "big pharma" have devoted a considerable amount of effort and resources to develop treatments and cures for EB. Such approaches include gene replacement and repair, protein replacement and cell-based therapies, and some are allele specific, requiring knowledge of mutant genes and specific mutations. A number of these strategies are in early clinical trials, and at least three are entering phase III for clinical testing in 2020. Considering the multiplicity of approaches, there is cautious optimism that some drugs may emerge in the near future as potential candidates for treatment of EB. It has also been suggested that, because of the complementary nature of these approaches, application of different drugs in combination may result in optimal treatment outcomes for an individual with EB [100].

Despite significant progress and relatively numerous ongoing clinical trials, the number of patients with EB who currently have access to molecular therapies is limited (Table 1). Current development is also primarily focused on DEB and JEB, whereas EBS, the most common EB type, has been largely neglected even though affected individuals are severely impaired in everyday life and professional activities. Furthermore, there are several questions regarding the cost of development and delivery of such 
pharmaceuticals and global access to these drugs once they are available in the market.

Regenerative medicine and replacement of the deficient genes and proteins are the only way to "cure" EB. Nevertheless, "adjuvant" therapies with less expensive repurposed drugs may assist in reducing disease severity and improving the quality of life of the affected individuals. In fact, such therapies may be required to complement strategies aimed at alleviating the fragility of the skin and mucous membranes as the primary pathologic process. Also, proving the efficacy of such measures seems challenging, and designing clinical trials with better endpoints and sufficient numbers of participants requires long-term expertise and international collaboration. Nevertheless, patients with EB and their families are looking forward to effective treatment, hopefully before too long.

Acknowledgements Carol Kelly assisted in manuscript preparation.

Funding Open Access funding provided by Projekt DEAL. The authors' original research was funded by the German Ministry for Education and Research (BMBF) (C.H.), the EB Research Partnership, the EB Medical Research Foundation, the Office of the Assistant Secretary of Defense for Health Affairs and the Defense Health Agency J9, Research and Development Directorate, through the Congressionally Directed Medical Research Program under Award No. W81XWH-18-1-0382 (all to A.P.S.) the National Institutes of Health of The United States Public Health Service (J.U.) and the Dystrophic Epidermolysis Bullosa Research Associations (DEBRA) of America and DEBRA International . Opinions, interpretations and recommendations are those of the authors and are not necessarily endorsed by the Department of Defense.

\section{Compliance with Ethical Standards}

Conflicts of interest C.H. was on the advisory board of Castle Creek Biosciences Inc. and A.P.S. owns stock in Krystal Biotech, Inc. J.U. has no conflicts of interest. That are Is Castle Creek Pharmaceuticals the same as the ,Castle Creek Biosciences' mentioned in Table 1 and Sect. 4.1? If so, which name should be used for consistency? directly relevant to the content of this article.

Open Access This article is licensed under a Creative Commons Attribution-NonCommercial 4.0 International License, which permits any non-commercial use, sharing, adaptation, distribution and reproduction in any medium or format, as long as you give appropriate credit to the original author(s) and the source, provide a link to the Creative Commons licence, and indicate if changes were made. The images or other third party material in this article are included in the article's Creative Commons licence, unless indicated otherwise in a credit line to the material. If material is not included in the article's Creative Commons licence and your intended use is not permitted by statutory regulation or exceeds the permitted use, you will need to obtain permission directly from the copyright holder.To view a copy of this licence, visit http://creativecommons.org/licenses/by-nc/4.0/.

\section{References}

1. Fine J-D, Bruckner-Tuderman L, Eady RAJ, Bauer EA, Bauer JW, Has C, et al. Inherited epidermolysis bullosa: updated recommendations on diagnosis and classification. J Am Acad Dermatol. 2014;70:1103-26.

2. Has C, Bauer JW, Bodemer C, Bolling M, Bruckner-Tuderman L, Diem A, et al. Consensus re-classification of inherited epidermolysis bullosa and other disorders with skin fragility. $\mathrm{Br}$ J Dermatol. 2020.

3. Uitto J, Bruckner-Tuderman L, McGrath JA, Riedl R, Robinson C. EB2017-progress in epidermolysis bullosa research toward treatment and cure. J Invest Dermatol. 2018;138:1010-6.

4. Schwieger-Briel A, Weibel L, Chmel N, Leppert J, KernlandLang K, Grüninger G, et al. A COL7A1 variant leading to in-frame skipping of exon 15 attenuates disease severity in recessive dystrophic epidermolysis bullosa. Br J Dermatol. 2015;173:1308-11.

5. Kiritsi D, Kern JS, Schumann H, Kohlhase J, Has C, Bruckner-Tuderman L. Molecular mechanisms of phenotypic variability in junctional epidermolysis bullosa. J Med Genet. 2011;48:450-7.

6. Mellerio JE, Pulkkinen L, McMillan JR, Lake BD, Horn HM, Tidman MJ, et al. Pyloric atresia-junctional epidermolysis bullosa syndrome: mutations in the integrin beta4 gene (ITGB4) in two unrelated patients with mild disease. Br J Dermatol. 1998;139:862-71.

7. Hoffmann J, Casetti F, Reimer A, Leppert J, Grüninger G, Has C. A silent COL17A1 variant alters splicing and causes junctional epidermolysis bullosa. Acta Derm Venereol. 2019;99:460-1.

8. Titeux M, Pendaries V, Tonasso L, Decha A, Bodemer C, Hovnanian A. A frequent functional SNP in the MMP1 promoter is associated with higher disease severity in recessive dystrophic epidermolysis bullosa. Hum Mutat. 2008;29:267-76.

9. Odorisio T, Di Salvio M, Orecchia A, Di Zenzo G, Piccinni E, Cianfarani F, et al. Monozygotic twins discordant for recessive dystrophic epidermolysis bullosa phenotype highlight the role of TGF- $\beta$ signalling in modifying disease severity. Hum Mol Genet. 2014;23:3907-22.

10. Vahidnezhad H, Youssefian L, Saeidian AH, Touati A, Sotoudeh S, Jazayeri A, et al. Next generation sequencing identifies double homozygous mutations in two distinct genes (EXPH5 and COL17A1) in a patient with concomitant simplex and junctional epidermolysis bullosa. Hum Mutat. 2018;39:1349-54.

11. Vahidnezhad H, Youssefian L, Sotoudeh S, Liu L, Guy A, Lovell PA, et al. Genomics-based treatment in a patient with two overlapping heritable skin disorders: Epidermolysis bullosa and acrodermatitis enteropathica. Hum Mutat. 2020;41:906-12.

12. Maccari ME, Speckmann C, Heeg M, Reimer A, Casetti F, Has $\mathrm{C}$, et al. Profound immunodeficiency with severe skin disease explained by concomitant novel CARMIL2 and PLEC1 loss-of-function mutations. Clin Immunol Orlando Fla. 2019;208:108228.

13. Wally V, Lettner T, Peking P, Peckl-Schmid D, Murauer EM, Hainzl S, et al. The pathogenetic role of IL-1 $\beta$ in severe epidermolysis bullosa simplex. J Invest Dermatol. 2013;133:1901-3.

14. Chacón-Solano E, León C, Díaz F, García-García F, García M, Escámez MJ, et al. Fibroblasts activation and abnormal extracellular matrix remodelling as common hallmarks in three cancer-prone genodermatoses. Br J Dermatol. 2019;181:512-22. 
15. Annicchiarico G, Morgese MG, Esposito S, Lopalco G, Lattarulo M, Tampoia M, et al. Proinflammatory cytokines and antiskin autoantibodies in patients with inherited epidermolysis bullosa. Medicine (Baltimore). 2015;94:e1528.

16. Reimer A, Hess M, Schwieger-Briel A, Kiritsi D, Schauer F, Schumann $\mathrm{H}$, et al. Natural history of growth and anaemia in children with epidermolysis bullosa: a retrospective cohort study. Br J Dermatol. 2019.

17. Fine JD, Johnson LB, Weiner M, Li KP, Suchindran C. Epidermolysis bullosa and the risk of life-threatening cancers: the National EB Registry experience, 1986-2006. J Am Acad Dermatol. 2009;60:203-11.

18. Has C, Castiglia D, del Rio M, Diez MG, Piccinni E, Kiritsi D, et al. Kindler syndrome: extension of FERMT1 mutational spectrum and natural history. Hum Mutat. 2011;32:1204-12.

19. Saleva M, Has C, He Y, Vassileva S, Balabanova M, Miteva L. Natural history of Kindler syndrome and propensity for skin cancer-case report and literature review. J Dtsch Dermatol Ges J Ger Soc Dermatol JDDG. 2018;16:338-41.

20. Cogan J, Weinstein J, Wang X, Hou Y, Martin S, South AP, et al. Aminoglycosides restore full-length type VII collagen by overcoming premature termination codons: therapeutic implications for dystrophic epidermolysis bullosa. Mol Ther J Am Soc Gene Ther. 2014;22:1741-52.

21. Lincoln V, Cogan J, Hou Y, Hirsch M, Hao M, Alexeev V, et al. Gentamicin induces LAMB3 nonsense mutation readthrough and restores functional laminin 332 in junctional epidermolysis bullosa. Proc Natl Acad Sci USA. 2018;115:E6536-45.

22. Woodley DT, Cogan J, Hou Y, Lyu C, Marinkovich MP, Keene $\mathrm{D}$, et al. Gentamicin induces functional type VII collagen in recessive dystrophic epidermolysis bullosa patients. J Clin Invest. 2017;127:3028-38.

23. Atanasova VS, Jiang Q, Prisco M, Gruber C, Piñón Hofbauer $\mathrm{J}$, Chen M, et al. Amlexanox enhances premature termination codon read-through in COL7A1 and expression of full length type VII Collagen: potential therapy for recessive dystrophic epidermolysis bullosa. J Invest Dermatol. 2017;137:1842-9.

24. Bornert O, Peking P, Bremer J, Koller U, van den Akker PC, Aartsma-Rus A, et al. RNA-based therapies for genodermatoses. Exp Dermatol. 2017;26:3-10.

25. Peking P, Breitenbach JS, Ablinger M, Muss WH, Poetschke FJ, Kocher T, et al. An ex vivo RNA trans-splicing strategy to correct human generalized severe epidermolysis bullosa simplex. $\mathrm{Br}$ J Dermatol. 2019;180:141-8.

26. Kocher T, Peking P, Klausegger A, Murauer EM, Hofbauer JP, Wally V, et al. Cut and paste: efficient homology-directed repair of a dominant negative KRT14 mutation via CRISPR/Cas9 nickases. Mol Ther J Am Soc Gene Ther. 2017;25:2585-98.

27. Marinkovich MP, Tang JY. Gene therapy for epidermolysis bullosa. J Invest Dermatol. 2019;139:1221-6.

28. Rashidghamat E, McGrath JA. Novel and emerging therapies in the treatment of recessive dystrophic epidermolysis bullosa. Intractable Rare Dis Res. 2017;6:6-20.

29. Eichstadt S, Barriga M, Ponakala A, Teng C, Nguyen NT, Siprashvili Z, et al. Phase 1/2a clinical trial of gene-corrected autologous cell therapy for recessive dystrophic epidermolysis bullosa. JCI Insight. 2019;4:e130554.

30. Siprashvili Z, Nguyen NT, Gorell ES, Loutit K, Khuu P, Furukawa LK, et al. Safety and wound outcomes following genetically corrected autologous epidermal grafts in patients with recessive dystrophic epidermolysis bullosa. JAMA. 2016;316:1808-17.

31. Kolodka TM, Garlick JA, Taichman LB. Evidence for keratinocyte stem cells in vitro: long term engraftment and persistence of transgene expression from retrovirus-transduced keratinocytes. Proc Natl Acad Sci USA. 1998;95:4356-61.
32. Supp DM, Hahn JM, Combs KA, McFarland KL, Schwentker A, Boissy RE, et al. Collagen VII expression is required in both keratinocytes and fibroblasts for anchoring fibril formation in bilayer engineered skin substitutes. Cell Transpl. 2019;28:1242-56.

33. Gaucher S, Lwin SM, Titeux M, Abdul-Wahab A, Pironon N, Izmiryan A, et al. EBGene trial: patient preselection outcomes for the European GENEGRAFT ex vivo phase I/II gene therapy trial for recessive dystrophic epidermolysis bullosa. Br J Dermatol. 2020;182:794-7.

34. Mavilio F, Pellegrini G, Ferrari S, Di Nunzio F, Di Iorio E, Recchia A, et al. Correction of junctional epidermolysis bullosa by transplantation of genetically modified epidermal stem cells. Nat Med. 2006;12:1397-402.

35. Bauer JW, Koller J, Murauer EM, De Rosa L, Enzo E, Carulli $\mathrm{S}$, et al. Closure of a large chronic wound through transplantation of gene-corrected epidermal stem cells. J Invest Dermatol. 2017;137:778-81.

36. Hirsch T, Rothoeft T, Teig N, Bauer JW, Pellegrini G, De Rosa $\mathrm{L}$, et al. Regeneration of the entire human epidermis using transgenic stem cells. Nature. 2017;551:327-32.

37. Liu N, Matsumura H, Kato T, Ichinose S, Takada A, Namiki $\mathrm{T}$, et al. Stem cell competition orchestrates skin homeostasis and ageing. Nature. 2019;568:344-50.

38. De Rosa L, Secone Seconetti A, De Santis G, Pellacani G, Hirsch T, Rothoeft T, et al. Laminin 332-dependent YAP dysregulation depletes epidermal stem cells in junctional epidermolysis bullosa. Cell Rep. 2019;27(2036-2049):e6.

39. Bonafont J, Mencía Á, García M, Torres R, Rodríguez S, Carretero M, et al. Clinically relevant correction of recessive dystrophic epidermolysis bullosa by dual sgRNA CRISPR/ Cas9-mediated gene editing. Mol Ther J Am Soc Gene Ther. 2019;27:986-98.

40. Hainzl S, Peking P, Kocher T, Murauer EM, Larcher F, Del Rio $\mathrm{M}$, et al. COL7A1 editing via CRISPR/Cas9 in recessive dystrophic epidermolysis bullosa. Mol Ther J Am Soc Gene Ther. 2017;25:2573-84.

41. Izmiryan A, Ganier C, Bovolenta M, Schmitt A, Mavilio F, Hovnanian A. Ex vivo COL7A1 correction for recessive dystrophic epidermolysis bullosa using CRISPR/Cas9 and homology-directed repair. Mol Ther Nucleic Acids. 2018;12:554-67.

42. Jacków J, Guo Z, Hansen C, Abaci HE, Doucet YS, Shin JU, et al. CRISPR/Cas9-based targeted genome editing for correction of recessive dystrophic epidermolysis bullosa using iPS cells. Proc Natl Acad Sci USA. 2019;116:26846-52.

43. Takashima S, Shinkuma S, Fujita Y, Nomura T, Ujiie H, Natsuga $K$, et al. Efficient gene reframing therapy for recessive dystrophic epidermolysis bullosa with CRISPR/Cas9. J Invest Dermatol. 2019;139(1711-1721):e4.

44. March OP, Kocher T, Koller U. Context-dependent strategies for enhanced genome editing of genodermatoses. Cells. 2020;9:112.

45. Umegaki-Arao N, Pasmooij AMG, Itoh M, Cerise JE, Guo Z, Levy B, et al. Induced pluripotent stem cells from human revertant keratinocytes for the treatment of epidermolysis bullosa. Sci Transl Med. 2014;6:264ra164.

46. Jonkman MF, Scheffer H, Stulp R, Pas HH, Nijenhuis M, Heeres $\mathrm{K}$, et al. Revertant mosaicism in epidermolysis bullosa caused by mitotic gene conversion. Cell. 1997;88:543-51.

47. Pasmooij AM, Jonkman MF, Uitto J. Revertant mosaicism in heritable skin diseases: mechanisms of natural gene therapy. Discov Med. 2012;14:167-79.

48. Kiritsi D, Garcia M, Brander R, Has C, Meijer R, Jose Escamez $\mathrm{M}$, et al. Mechanisms of natural gene therapy in dystrophic epidermolysis bullosa. J Invest Dermatol. 2014;134:2097-104. 
49. Pasmooij AM, Pas HH, Bolling MC, Jonkman MF. Revertant mosaicism in junctional epidermolysis bullosa due to multiple correcting second-site mutations in LAMB3. J Clin Invest. 2007;117:1240-8.

50. Pasmooij AM, Nijenhuis M, Brander R, Jonkman MF. Natural gene therapy may occur in all patients with generalized nonHerlitz junctional epidermolysis bullosa with COL17A1 mutations. J Invest Dermatol. 2012;132:1374-83.

51. Twaroski K, Eide C, Riddle MJ, Xia L, Lees CJ, Chen W, et al. Revertant mosaic fibroblasts in recessive dystrophic epidermolysis bullosa. Br J Dermatol. 2019;181:1247-53.

52. Gostynski A, Pasmooij AM, Jonkman MF. Successful therapeutic transplantation of revertant skin in epidermolysis bullosa. J Am Acad Dermatol. 2014;70:98-101.

53. Yuen WY, Huizinga J, Jonkman MF. Punch grafting of chronic ulcers in patients with laminin-332-deficient, nonHerlitz junctional epidermolysis bullosa. J Am Acad Dermatol. 2013;68:93-7 (97 e1-2).

54. Rodrigues M, Yokota T. An overview of recent advances and clinical applications of exon skipping and splice modulation for muscular dystrophy and various genetic diseases. Methods Mol Biol Clifton NJ. 2018;1828:31-55.

55. McGrath JA, Ashton GH, Mellerio JE, Salas-Alanis JC, Swensson O, McMillan JR, et al. Moderation of phenotypic severity in dystrophic and junctional forms of epidermolysis bullosa through in-frame skipping of exons containing non-sense or frameshift mutations. J Invest Dermatol. 1999;113:314-21.

56. Kowalewski C, Bremer J, Gostynski A, Wertheim-Tysarowska K, Wozniak K, Bal J, et al. Amelioration of junctional epidermolysis bullosa due to exon skipping. Br J Dermatol. 2016;174:1375-9.

57. Bremer J, van der Heijden EH, Eichhorn DS, Meijer R, Lemmink $\mathrm{HH}$, Scheffer H, et al. Natural exon skipping sets the stage for exon skipping as therapy for dystrophic epidermolysis bullosa. Mol Ther Nucleic Acids. 2019;18:465-75.

58. Turczynski S, Titeux M, Tonasso L, Décha A, Ishida-Yamamoto A, Hovnanian A. Targeted exon skipping restores type VII collagen expression and anchoring fibril formation in an in vivo RDEB model. J Invest Dermatol. 2016;136:2387-95.

59. Bremer J, Bornert O, Nyström A, Gostynski A, Jonkman MF, Aartsma-Rus A, et al. Antisense oligonucleotide-mediated exon skipping as a systemic therapeutic approach for recessive dystrophic epidermolysis bullosa. Mol Ther Nucleic Acids. 2016;5:e379.

60. Bornert O, Kühl T, Bremer J, van den Akker PC, Pasmooij AM, Nyström A. Analysis of the functional consequences of targeted exon deletion in COL7A1 reveals prospects for dystrophic epidermolysis bullosa therapy. Mol Ther J Am Soc Gene Ther. 2016;24:1302-11.

61. Goto M, Sawamura D, Nishie W, Sakai K, McMillan JR, Akiyama M, et al. Targeted skipping of a single exon harboring a premature termination codon mutation: implications and potential for gene correction therapy for selective dystrophic epidermolysis bullosa patients. J Invest Dermatol. 2006;126:2614-20.

62. Woodley DT, Keene DR, Atha T, Huang Y, Lipman K, Li W, et al. Injection of recombinant human type VII collagen restores collagen function in dystrophic epidermolysis bullosa. Nat Med. 2004;10:693-5.

63. Woodley DT, Wang X, Amir M, Hwang B, Remington J, Hou Y, et al. Intravenously injected recombinant human type VII collagen homes to skin wounds and restores skin integrity of dystrophic epidermolysis bullosa. J Invest Dermatol. 2013;133:1910-3.

64. Tamai K, Yamazaki T, Chino T, Ishii M, Otsuru S, Kikuchi Y, et al. PDGFRalpha-positive cells in bone marrow are mobilized by high mobility group box 1 (HMGB1) to regenerate injured epithelia. Proc Natl Acad Sci USA. 2011;108:6609-14.
65. Aikawa E, Fujita R, Kikuchi Y, Kaneda Y, Tamai K. Systemic high-mobility group box 1 administration suppresses skin inflammation by inducing an accumulation of PDGFR $\alpha(+)$ mesenchymal cells from bone marrow. Sci Rep. 2015;5:11008.

66. Kido T, Miyagawa S, Goto T, Tamai K, Ueno T, Toda K, et al. The administration of high-mobility group box 1 fragment prevents deterioration of cardiac performance by enhancement of bone marrow mesenchymal stem cell homing in the delta-sarcoglycan-deficient hamster. PLoS One. 2018;13:e0202838.

67. Shimbo T, Yamazaki S, Wang X, Kikuchi Y, Bruckner-Tuderman L, Kaneda Y, et al. 906 Systemic HMGB1 administration ameliorates cutaneous and non-cutaneous manifestations in a dystrophic epidermolysis bullosa model mouse. J Invest Dermatol. 2017;137:S156.

68. Welch EM, Barton ER, Zhuo J, Tomizawa Y, Friesen WJ, Trifillis P, et al. PTC124 targets genetic disorders caused by nonsense mutations. Nature. 2007;447:87-91.

69. McElroy SP, Nomura T, Torrie LS, Warbrick E, Gartner U, Wood $\mathrm{G}$, et al. A lack of premature termination codon read-through efficacy of PTC124 (Ataluren) in a diverse array of reporter assays. PLoS Biol. 2013;11:e1001593.

70. Walker PD, Shah SV. Evidence suggesting a role for hydroxyl radical in gentamicin-induced acute renal failure in rats. J Clin Invest. 1988;81:334-41.

71. Gonzalez-Hilarion S, Beghyn T, Jia J, Debreuck N, Berte G, Mamchaoui K, et al. Rescue of nonsense mutations by amlexanox in human cells. Orphanet J Rare Dis. 2012;7:58.

72. Atanasova VS, Russell RJ, Webster TG, Cao Q, Agarwal P, Lim $\mathrm{YZ}$, et al. Thrombospondin- 1 is a major activator of TGF- $\beta$ signaling in recessive dystrophic epidermolysis bullosa fibroblasts. J Invest Dermatol. 2019;139(1497-1505):e5.

73. Nyström A, Velati D, Mittapalli VR, Fritsch A, Kern JS, Bruckner-Tuderman L. Collagen VII plays a dual role in wound healing. J Clin Invest. 2013;123:3498-509.

74. Nyström A, Bruckner-Tuderman L. Injury- and inflammationdriven skin fibrosis: the paradigm of epidermolysis bullosa. Matrix Biol J Int Soc Matrix Biol. 2018;68-69:547-60.

75. Ng YZ, Pourreyron C, Salas-Alanis JC, Dayal JH, Cepeda-Valdes $\mathrm{R}$, Yan W, et al. Fibroblast-derived dermal matrix drives development of aggressive cutaneous squamous cell carcinoma in patients with recessive dystrophic epidermolysis bullosa. Cancer Res. 2012;72:3522-34.

76. Shi Y, Massagué J. Mechanisms of TGF-beta signaling from cell membrane to the nucleus. Cell. 2003;113:685-700.

77. Connolly EC, Freimuth J, Akhurst RJ. Complexities of TGF- $\beta$ targeted cancer therapy. Int J Biol Sci. 2012;8:964-78.

78. Nyström A, Thriene K, Mittapalli V, Kern JS, Kiritsi D, Dengjel $\mathrm{J}$, et al. Losartan ameliorates dystrophic epidermolysis bullosa and uncovers new disease mechanisms. EMBO Mol Med. 2015;7:1211-28.

79. Cianfarani F, De Domenico E, Nyström A, Mastroeni S, Abeni $\mathrm{D}$, Baldini E, et al. Decorin counteracts disease progression in mice with recessive dystrophic epidermolysis bullosa. Matrix Biol J Int Soc Matrix Biol. 2019;81:3-16.

80. Mellerio JE, Robertson SJ, Bernardis C, Diem A, Fine JD, George R, et al. Management of cutaneous squamous cell carcinoma in patients with epidermolysis bullosa: best clinical practice guidelines. Br J Dermatol. 2016;174:56-67.

81. Ciardiello F, Tortora G. EGFR antagonists in cancer treatment. N Engl J Med. 2008;358:1160-74.

82. Medek K, Koelblinger P, Koller J, Diem A, Ude-Schoder K, Bauer JW, et al. Wundheilungsstörungen während der antitumorösen Therapie mit Cetuximab bei schwerer generalisierter dystropher Epidermolysis bullosa. J Dtsch Dermatol Ges J Ger Soc Dermatol JDDG. 2019;17:448-50. 
83. Arnold AW, Bruckner-Tuderman L, Zuger C, Itin PH. Cetuximab therapy of metastasizing cutaneous squamous cell carcinoma in a patient with severe recessive dystrophic epidermolysis bullosa. Dermatol Basel Switz. 2009;219:80-3.

84. Kim M, Li M, Intong LRA, Tran K, Melbourne W, Marucci $\mathrm{D}$, et al. Use of cetuximab as an adjuvant agent to radiotherapy and surgery in recessive dystrophic epidermolysis bullosa with squamous cell carcinoma. Br J Dermatol. 2013;169:208-10.

85. Reimer A, Lu S, He Y, Bruckner-Tuderman L, Technau-Hafsi K, Meiss F, et al. Combined anti-inflammatory and low-dose antiproliferative therapy for squamous cell carcinomas in recessive dystrophic epidermolysis bullosa. J Eur Acad Dermatol Venereol JEADV. 2020;34:e1-3.

86. Diociaiuti A, Steinke H, Nyström A, Schwieger-Briel A, Meiss F, Pfannenberg C, et al. EGFR inhibition for metastasized cutaneous squamous cell carcinoma in dystrophic epidermolysis bullosa. Orphanet J Rare Dis. 2019;14:278.

87. Ferris RL, Blumenschein G, Fayette J, Guigay J, Colevas AD, Licitra L, et al. Nivolumab for recurrent squamous-cell carcinoma of the head and neck. N Engl J Med. 2016;375:1856-67.

88. Migden MR, Rischin D, Schmults CD, Guminski A, Hauschild A, Lewis KD, et al. PD-1 blockade with cemiplimab in advanced cutaneous squamous-cell carcinoma. N Engl J Med. 2018;379:341-51.

89. Fine JD, Johnson LB, Weiner M, Stein A, Suchindran C. Chemoprevention of squamous cell carcinoma in recessive dystrophic epidermolysis bullosa: results of a phase 1 trial of systemic isotretinoin. J Am Acad Dermatol. 2004;50:563-71.

90. Atanasova VS, Pourreyron C, Farshchian M, Lawler M, Brown CA, Watt SA, et al. Identification of rigosertib for the treatment of recessive dystrophic epidermolysis bullosa-associated squamous cell carcinoma. Clin Cancer Res Off J Am Assoc Cancer Res. 2019;25:3384-91.

91. Prodinger C, Reichelt J, Bauer JW, Laimer M. Epidermolysis bullosa: advances in research and treatment. Exp Dermatol. 2019;28:1176-89.
92. Lwin SM, Syed F, Di W-L, Kadiyirire T, Liu L, Guy A, et al. Safety and early efficacy outcomes for lentiviral fibroblast gene therapy in recessive dystrophic epidermolysis bullosa. JCI Insight. 2019;4:e126243.

93. Osborn MJ, Lees CJ, McElroy AN, Merkel SC, Eide CR, Mathews W, et al. CRISPR/Cas9-based cellular engineering for targeted gene overexpression. Int J Mol Sci. 2018;19:946.

94. Webber BR, Osborn MJ, McElroy AN, Twaroski K, Lonetree C-L, DeFeo AP, et al. CRISPR/Cas9-based genetic correction for recessive dystrophic epidermolysis bullosa. NPJ Regen Med. 2016;1:16014.

95. Shinkuma S, Guo Z, Christiano AM. Site-specific genome editing for correction of induced pluripotent stem cells derived from dominant dystrophic epidermolysis bullosa. Proc Natl Acad Sci USA. 2016;113:5676-81.

96. Wu W, Lu Z, Li F, Wang W, Qian N, Duan J, et al. Efficient in vivo gene editing using ribonucleoproteins in skin stem cells of recessive dystrophic epidermolysis bullosa mouse model. Proc Natl Acad Sci USA. 2017;114:1660-5.

97. Benati D, Miselli F, Cocchiarella F, Patrizi C, Carretero M, Baldassarri S, et al. CRISPR/Cas9-mediated in situ correction of LAMB3 gene in keratinocytes derived from a junctional epidermolysis bullosa patient. Mol Ther J Am Soc Gene Ther. 2018;26:2592-603.

98. Tockner B, Kocher T, Hainzl S, Reichelt J, Bauer JW, Koller U, et al. Construction and validation of an RNA trans-splicing molecule suitable to repair a large number of COL7A1 mutations. Gene Ther. 2016;23:775-84.

99. Peking P, Koller U, Duarte B, Murillas R, Wolf S, Maetzig T, et al. An RNA-targeted therapy for dystrophic epidermolysis bullosa. Nucleic Acids Res. 2017;45:10259-69.

100. Mellerio J, Uitto J. Meeting report: The first global congress on epidermolysis bullosa, EB2020 -Toward treatment and cure. J Invest Dermatol (in press). 